*E. Yuon, M. Soukhanov, K. Markov, (SRC VNIIgeosystem)

\title{
SUMMARY
}

The National geological cartographic information system is intended for integration of geological maps into the unified technological environment and creation of multiscale geological coverage of Russian Federation. At the same time, the system allows to integrate this digital coverage into the international projects, including OneGeology and OneGeology-Europe, using the international formats of data providing.

The full capabilities could be realised with using MGS - multifunctional geoinformation server. This platform provides realisation of multiuser internet access to the distributed digital geological information resources, integration of heterogeneous geological data, distributed data processing, including spatial analysis and data modeling.

Integration of NGCIS resources into the international projects could be reached due to application of modern data transfer protocols (WFS, WMS, CSW), and also modern standardised formats of geological data providing and interchange, including GeoSciML - spatial data format to deliver geological data as an XML-document.

\section{Технологічні можливості представлення даних НГК IC засобами МГС з використанням міжнародних стандартів}

*Є.М. Юон, М.Г. Суханов, К.М. Марков, (Всеросійський науково-дослідний інститут геологічних, геофізичних і геохімічних систем (ВНИИгеосистем))

\section{РЕЗЮМЕ}

Макет Національної геолого-картографічної інформаційної системи (НГК IC) призначений для інтеграції геологічних карт в єдине програмно-технологічне середовище і створення полімасштабного геологічного покриття території Російської Федерації. При цьому система має на увазі можливість інтеграції цифрових геологічних карт в міжнародні проекти, в тому числі OneGeology i OneGeology-Europe, на основі міжнародних форматів представлення даних. Повною мірою дані можливості можуть бути реалізовані з використанням програмнотехнологічної платформи БГС (багатофункціональний геоінформаційний сервер). Даний комплекс забезпечує реалізацію віддаленого багатокористувацького Інтернет-доступу до розподілених цифрових геологічних інформаційних ресурсів, інтеграцію різнорідних інформаційних систем і даних в єдине технологічне середовище, розподілену обробку інформації методами просторового аналізу і моделювання для оперативної підтримки прийняття управлінських рішень. Інтеграція інформаційних ресурсів НГК IC до складу міжнародних проектів забезпечується за рахунок використання в БГС сучасних протоколів передачі даних (WMS, WFS, CSW), а також застосування сучасних стандартизованих форматів зберігання і представлення геологічних даних, включаючи GeoSciML - спеціалізований формат представлення геологічних даних у вигляді структурованого XML-документа. 


\section{Технологические возможности представления данных НГК ИС} средствами МГС с использованием международных стандартов

*Е.М. Юон, М.Г. Суханов, К.Н. Марков, (ФГУП ГНЦ РФ ВНИИгеосистем)

\section{РЕЗЮМЕ}

Макет Национальной геолого-картографической информационной системы (HГК ИС) предназначен для интеграции геологических карт в единую программно-технологическую среду и создания полимасштабного геологического покрытия территории Российской Федерации. При этом система подразумевает возможность интеграции цифровых геологических карт в международные проекты, в том числе OneGeology и OneGeology-Europe, на основе международных форматов представления данных.

В полной мере данные возможности могут быть реализованы с использованием программнотехнологической платформы МГС (многофункциональный геоинформационный сервер). Данный комплекс обеспечивает реализацию удаленного многопользовательского Интернетдоступа к распределенным цифровым геологическим информационным ресурсам, интеграцию разнородных информационных систем и данных в единую технологическую среду, распределенную обработку информации методами пространственного анализа и моделирования для оперативной поддержки принятия управленческих решений.

Интеграция информационных ресурсов НГК ИС В состав международных проектов обеспечивается за счет использования в МГС современных протоколов передачи данных (WMS, WFS, CSW), а также применения современных стандартизированных форматов хранения и представления геологических данных, включая GeoSciML - специализированный формат представления геологических данных в виде структурированного XML-документа. 


\section{Представление данных НГК ИС средствами МГС}

Макет Национальной геолого-картографической информационной системы (НГК ИС, ВСЕГЕИ) предназначен для интеграции геологических карт в единую программнотехнологическую среду и создания полимасштабного геологического покрытия территории Российской Федерации и ее континентального шельфа. Ключевыми особенностями системы является возможность многопользовательского доступа к этим картам по локальным и глобальным компьютерным сетям, а также возможность интеграции цифровых геологических карт в международные проекты, в том числе OneGeology и OneGeology-Europe, на основе международных форматов представления данных.

В полной мере данные возможности могут быть реализованы с использованием программно-технологической платформы МГС (многофункциональный геоинформационный сервер, ВНИИгеосистем). Данный комплекс обеспечивает реализацию удаленного многопользовательского Интернет-доступа к распределенным цифровым геологическим информационным ресурсам, интеграцию разнородных, в том числе уже существующих, информационных систем и данных в единую технологическую среду, распределенную обработку информации методами пространственного анализа и моделирования для оперативной поддержки принятия управленческих решений.

Унифицированная программно-технологическая среда МГС разработана на средствах разработки интернет-ГИС, реализующих стандарты и службы описания и обмена пространственно привязанной информацией ISO/OGC.

Коммуникационная инфраструктура системы опирается на стандарты, протоколы и форматы данных интернета, а также совместима со стандартными программными средствами работы пользователя с интернетом (веб-броузеры).

Интеграция информационных ресурсов НГК ИС в состав международных проектов обеспечивается за счет использования в МГС современных протоколов передачи данных (WMS, WFS, CSW), а также применения современных стандартизированных форматов хранения и представления геологических данных, включая GeoSciML - специализированный формат представления геологических данных в виде структурированного XML-документа. GeoSciML разрабатывается широким сообществом ученых-геологов по всему миру, включая специалистов ведущих национальных геологических служб. При этом, данный формат не является структурой базы данных - он лишь позволяет обеспечить стандартизированный доступ к разнородным пользовательским геологическим данным. Внедрение GeoSciML обеспечивается за счет настройки его логической модели на структуру базы данных, используемой в НГК ИС. Данная настройка подразумевает сопоставление элементов и атрибутов логической модели языка со структурой и составом атрибутивных таблиц базы данных. При этом, сопоставление подразумевает как корреляцию логических моделей, так и увязку содержимого базы данных с составом международных словарей и классификаторов.

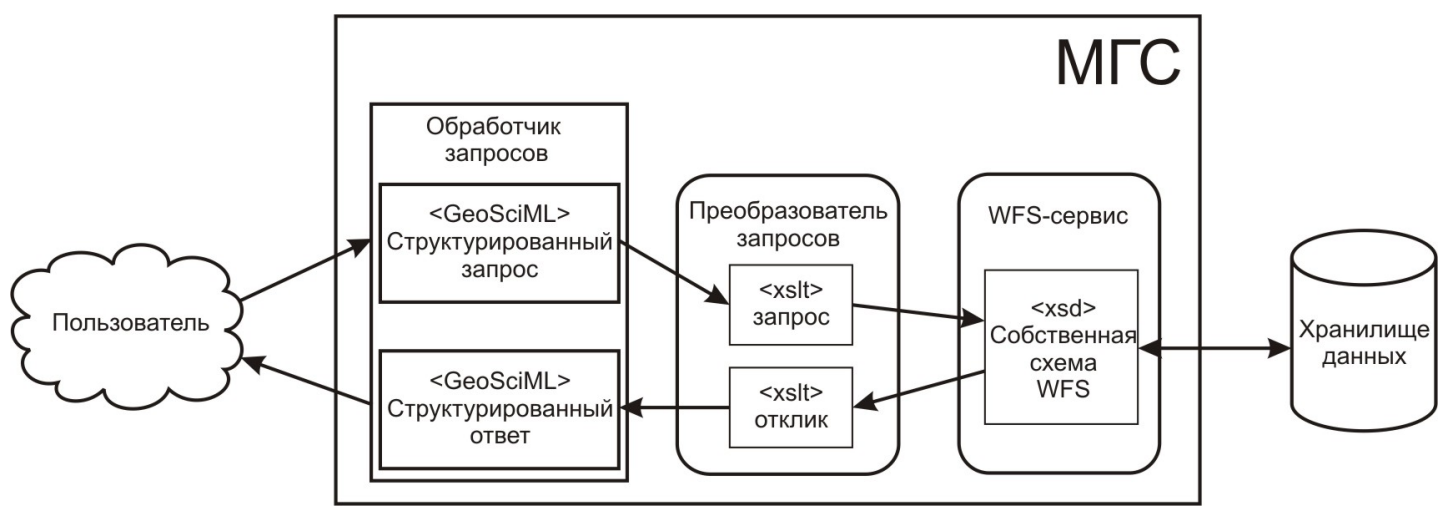

Рисунок 1 Схема прохождения запроса от пользователя $\kappa$ базе данных и обратно, посредством МГС. 